\title{
The CSR in SMEs: A Case Study
}

\author{
Ornella Malandrino \\ Maria Rosaria Garofalo
}

Daniela Sica

\author{
Maria Rosaria Sessa \\ Department of Business Sciences \\ Management \& Innovation Systems (DISA-MIS) \\ University of Salerno \\ Italy \\ Stefania Supino \\ University of San Raffaele, Rome \\ Italy
}

\begin{abstract}
The changes that over time have marked our economic systems, have created new requirements relating to ball ethical-social and environmental issues, which the business community, in the first place, has had to cope with a shift of its organizational and managerial models. This paper aims to examine, in the first part, the path that has characterized the enlargement of the corporate vision and its responsibility toward the aspects related to the ethical dimension, social and environmental impact, in addition to those of traditional economic and financial. In the second part it analyzes the adoption of systems, models and tools of CSR in the Italian company "Antonio Petti SpA" operates from 1925 in the sector of vegetable tinned. This in order to evaluate the contribution that CSR instrument adopted has offered to build organization's sustainability in its three dimension: economic, environmental and social.
\end{abstract}

Keywords: Corporate Social Responsibility, value creation, socio-environmental tools, Ethical code

\section{Introduction}

The progressive extension of "social responsibility" to the business world is defining a challenging role for the business community from which a rethinking of the same goals that businesses are called to pursue. In fact, alongside the traditional production function, which still represents the constitutive element of their being and operates, they are asked to drive to sustainability, in the context of enhancing economic, human and natural. According to this extension, social responsibility and sustainability are increasingly closely linked to both positive and normative assessment.

Similarly, stakeholders are now more involved in taking behaviors in line with the principles of sustainability and, above all, acquiring propositional and coherent attitudes in relevant processes for the purpose of concrete social innovation. Due to the central role of the stakeholders, a reinterpretation of Social Responsibility is being drawn up, from Corporate Social Responsibility to Company Stakeholder Responsibility, through an approach that favors sustainability as a correct, fair and transparent form of value creation for all heterogeneous types of stakeholders.

Has emerged, therefore, the need to improve information flows on performance and socio-environmental organization, in the awareness that the traditional accounting documents of an economic nature have significant limits in accounting for the multiplicity of intangible assets such as reputation, trust, and consensus. In fact, although they make a significant contribution to the process of creating wealth generated by the company, they do not find adequate accounting in their operating budgets. 
It started a process aimed at the enlargement of the corporate information, which exceeded the now restricted, and strongly structured, the riverbed of the aspects connected to the balances economic-financial capital-to involve those linked to communication on social value of business.

All stakeholders, internal and external, financial and non-financial, have expressed this requirement of accountability and will participate in a concrete and coherent, in order to promote the transition from models based on Corporate Social Responsibility to other based on Company Stakeholders Responsibility. These models require, however, the involvement of small and medium-sized enterprises, through innovative approaches to RS, which do not involve the dissemination of practical "standard", but to promote an act of undertaking capable of successfully combine responsibility and competitiveness.

The aim of this paper is the critical analysis of the evolutionary dynamics that characterized the concept of Corporate Social Responsibility in order to scan a best practice of a south Italian SME. Therefore, the work is articulated into five sections. Initially, the contribution that various scholars have given over time to the concept of Corporate Social Responsibility, a multidimensional definition that is still evolving and, consequently, complex and difficult to operate. Subsequently, the main actions, models and tools were explored through which RS has now declined. They are essentially designed for and for large corporations, often operating in several countries and therefore more exposed to instances and, sometimes, pressure from stakeholders on environmental and social performance.

It has emerged that this set of tools is difficult to adopt by SMEs, which are the cornerstone of the European productive fabric and, in particular, Italian. SMEs are often characterized by a concrete social commitment, albeit unrecognizable, as it is characterized by an almost "intimate" declination, an expression of the entrepreneur's ideal thrust, who realizes social interventions by considering expressions of his own sphere rather than that of your organization.

However, the involvement of SMEs is needful for the "building" of lasting sustainability as it is capable of integrating growth in competitiveness, environmental protection and social development. This is because of the extraordinary synergies that may arise from the structured adoption of CRS-marked routes and the promotion of local development-oriented dynamics. Therefore, we analyzed the systems, management tools and standards for CSR adopted by an Italian PMI: the A. Petty S.p.A., in order to explore the opportunities and the main elements of criticality that derive from a strategic drive towards improving their performance in a holistic approach.

In the conclusions, finally, we present the future research dynamics that could be followed.

\section{Background}

The analysis of the "social perspective" of economic activities represents a theme explored for a long time, both in terms of the political-economic that under the legal-philosophical

However, only from the second half of the last century the scientific literature on the topic has also received contributions with a more pronounced applicative value.

This new approach has contributed significantly to the studies conducted since the 1950's in the United States, as well as the many theoretical address to Corporate Social Responsibility (CSR),also managerial studies, progressively realized in a wide and diverse range of operational tools. A first significant contribution to the CSR concept is from 1953commonly traced back to H. Bowen (1953) - considered the "father" of CSR -and the "duty of businessmen to pursue those policies, to make those decisions, to follow those lines of action which are desirable in the light of the objectives and the values recognized by society".

In this phase the scientific debate focuses on behavioral dimension of businessmen, able, with their choices, to orient the companies toward the assumption of Social Responsibility. Subsequently, in the 1960s, in parallel to the increase and the consolidation of the economic power of the undertakings, affirms the Corporate Social Responsibility. Moreover, the conflicting and critical positions concerning the contents and, indeed, the very existence of CSR have been various: amongst all, just remember the famous writings of the early sixties of M. Friedman. According to which "there is one and only one social responsibility of business to use its resources and engage in activities designed to increase its profits so long as it stays in the rules of the game, which is to say, engages in open and free competition, without deception or fraud" (Friedman 1962).

In spite of strong criticism, the culture of social responsibility has continued to spread, feeding a fertile debate not only in the academia but also between managers, institutions and public opinion. 
It is certainly attributable to A. B. Carrol (1979) one of the most significant contributions to this debate; he comes, in 1979, to distinguish between four types of entrepreneurial responsibility, in an attempt to reconcile economic objectives with social objectives.

The company has, in the first place, an economic responsibility for the production and sale of goods and services for the market, in exchange for profit. The company has also legal responsibilities, which require them to comply with the laws - issued by reference institutions - that regulate the competition. The other two types of responsibility go beyond what is expressly required by the economic-legal system and are thus characterized by volunteering. The ethical responsibility involves an entrepreneurial activity conforms to the values and social standards, such as equity, solidarity, justice and impartiality. The philanthropy responsibility, a character distinctly discretion, implies further benefit and investments in favor of the Community.

Subsequently, Carro 1 (1991) highlighted the hierarchical nature of the different types of responsibility, specifying that the first - at the basis of the so-called "corporate social responsibility pyramid" - is the economic one, followed by legal, ethical and philanthropic. In the field of managerial disciplines, the 1980 s will be remembered for being characterized by the progressive assertion of "stakeholder theory" by R.E. Freeman (1984).

Although the stakeholder concept was already outlined in a pioneering work of the Stanford Research Institute (now called SRI International) since 1963, and subsequently deepened by other management scholars, it is necessary to R.E. Freeman is the first theorist that identifies stakeholders as "any group or individual who can affect or is affected by the achievement of the organization's objectives" (Freeman 1984).

They are distinguished in primary and secondary, depending on whether their contribution is indispensable to the survival of the business organization. The stakeholder theory marks the affirmation of a new conception of the firm that sees it no longer monolithically oriented to satisfy the interests of a dominant core - such as shareholder - but open to an enhanced approach of relations and dialogue. The key element is the balancing of different interests and the expectations of all the parties involved in achieving its mission (Viviani 1999).

In this perspective, a managerial model emerges no longer based on the opposition between shareholders and stakeholders, rather than multistakeholders, aiming to internalize the values and expectations of all the protagonists of the social scene in corporate governance strategies. Through stakeholder management, the company can secure trust and consent from suppliers, customers, lenders, and the entire community, by creating and strengthening its reputation.

During the nineties, the theme of social responsibility has taken on a notable role in the strategies of organizations and, in particular, of entrepreneurship, for the widespread acquisition of the awareness of the urgency of guiding management models to the paradigm of sustainability, understood in the wide sense of balance between the economic dimension and the socio-environmental dimension.

In environmental policies, the integration of the traditional command and control approach - characterized by the use of legislation as a tool for control, control and sanction - is initiated with voluntary instruments.

However, the environmental challenge, placed in the scenario of sustainable development, represents the "bridge" towards the affirmation of a more comprehensive and global approach to sustainability. It drives the company towards wider responsibilities by defining a strategy that sees it engaging in multiple fronts related not only to the protection of the environment, but also to safety at work, business ethics, all equity and social solidarity.

In other words, the environmental sphere is towing and anticipating a more comprehensive approach to sustainability by businesses, enabling them to refine and improve business orientations and culture, in a sort of dynamic process aimed at raising the level of responsibility in Company comparisons. The company sustainable, therefore, is oriented to the creation of value widened and long-term for the entire stakeholders' network into which it is inserted and from which come the social and environmental issues (Nigro and Petracca 2016).

An important contribution to the affirmation of social responsibility was also offered by various international organizations that are committed to attempt to regulate the conduct of multinational companies. One of the most significant experiences is that of the United Nations that, through the first birth of its Agencies, the International Labor Office (ILO), approved in 1977 and subsequently revised, the Tripartite Declaration of Principles for Businesses Multinational and Social Policy (ILO 2017). 
This declaration expresses a multiplicity of principles in terms of employment, training, industrial relations, living and working conditions that governments, organizations of employers, workers and companies are invited to observe on a voluntary basis. Another major initiative of the United Nations is the Global Compact, a kind of "global pact" - launched in 1999 at the World Economic Forum in Davos by then Secretary General Kofi Annan and formally presented in 2000 at the Assembly of Nations Unite - expressed through ten universal principles to which companies must be inspired to promote sustainable growth dynamics.

The Organization for Economic Cooperation and Development (OECD) in 2000 also revised the Guidelines for Multinational Enterprises Abroad (already contained in the Declaration on International Investments and Multinational Enterprises, drafted in 1976) which set out principles responsible behavior on issues related to industrial relations, environment, competition, fight against corruption, taxation, etc.They are identified in a global code negotiated by governments which, at least theoretically, are committed to ensuring that companies comply with it.

The European Union also has made a decisive contribution to the affirmation of social responsibility, since the Lisbon Council of March 2000, when it was defined as a key instrument for the realization of a modern economic system, more competitive and socially cohesive. The European Commission's Green Paper of 2001, "Promoting a European framework for corporate social responsibility", is a cornerstone of the CSR concept, which, moreover, gives a broadly accepted definition today. Shared, namely: the voluntary integration of social and environmental concerns of businesses in their commercial operations and relations with stakeholders.

Social responsibility is expressed to employees and, more generally, to all parties involved in the activity of the undertaking, but which in turn can influence its success. To be socially responsible means not only fully fulfilling the applicable legal obligations, but going beyond, investing more in human capital, the environment and relations with other stakeholders" (European Commission 2001).

These documents contributed to an important debate on the company's social role, accompanied by a considerable initiatives and insights, a debate that involved very different areas, such as in which public entities, business associations and non-governmental organizations, trade unions and NGOs operate. While aware of the holistic dimension of CSR, it has usually declined an internal dimension and an external dimension. The first focuses on human resource management, worker health and safety, on improving the company's climate, on technological and organizational innovations to reduce the environmental impact generated by existing activities. The second, instead, is projected toward the improvement of the welfare of local communities, protecting human rights and protecting natural resources globally.

The internalisation of CSR in managerial frameworks - in its two dimensions, both internally and externally promotes processes of enhancing human resources, collaborating with other organizations and institutions and social dialogue, promoting the diffusion of participatory phenomena both at the level of enterprise, both in the socio-environmental context of reference.

It is, in fact, widespread belief that businesses that achieve positive results in the environmental and social field can only achieve better economic results by activating, in the medium to long term, virtuous circuits in terms of productivity, competitiveness and image (Cheng et al. 2014).

Therefore, the affirmation of responsible behaviors reveals new perspectives for organizations and, in particular, for businesses, even those of small and medium size that are increasingly called upon to play a protagonist role in a new economic scenario in which more and more it is strongly hoped that a widespread and lasting development will be realized.

\section{CSR: a review of the main tools}

The extension of the conceptual Quality framework is defining a business challenging role, resulting in a rethink about the goals the organizations have to pursue. In fact, in addition to the usual production function, which is their fundamental function, to the organizations has been asked to pay more attention to the sustainability matter enhancing contextually the economic capital, the human capital and the natural capital.

The correct approach to sustainability is based on the integration of a broader range of targets which, in addition to those considered traditional, as related to economic performances, will consider others related to environmental, ethical and social ones affirming the concept of Corporate Social Responsibility 
This implies, as mentioned above, an extension of the business responsibilities and horizons, through the adoption of ethical principlesin the management activities government.

In other words, it is gradually materializing the assertion in the economic activities of ethical values (such as respect for human rights and of the worker's dignity and health, equal opportunities, non-discrimination against women and minorities, etc.).

These recent responsibilities are reflected in emerging rating business procedures and evaluation, based on a set of economic, ethical and environmental criteria.

Over the last years, in fact, within the articulated process aimed at defining new voluntary instruments of socioenvironmental policy, the organizations, especially those characterized by guidelines more pro-active, have exceeded the defensive attitude which had previously characterized the interactions with the external environment. They are flocking, in fact, the adoption of collaborative and transparent approaches, involving new communication strategies with its stakeholders, strategies that represent the expression of the acquired awareness of intangible assets importance as the image, trust and the reputation, in the realization of profit and the ability to compete.

The reasons seem all too obvious: with its programs to implement Quality in its multiple facets (business, environmental, social) lead to the affirmation of the products (goods and services) in international markets, improve the undertaking's efficiency (at the production process level in the strict sense, as well as to organizational and management levels) and achieve, finally, the costs reduction through corrective actions, but above all implement prevention of possible inefficiencies.

The same Deming expresses himself about this, with great effectiveness so as to depict such concepts as a real "chain reaction", whose graphical representation has been brought to the attention of top managers since 1950, since it became even considered the basis for "a way of life".

It seems worthwhile to note that these schematic observations are valid for both large and smaller organizations, which by their greater flexibility can also get significant competitive advantages towards to external competitors. Businesses that occupy a leading position in the field of management geared toward Quality have certainly been able to realize huge benefits, as it emerged sometimes in a number of production companies, ranging from electronics to the service sector, the machine tools industry, the automotive and manufacturing.

In this view, the presence of a wide variety of CSR instruments does not encourage a correct and effective application, facilitates understanding and the real scope, because they are based on "environmental" and/or "ethical" criteria.

Therefore, the attempt to provide a framework of CSR tools as exhaustive as possible in a given space-time could be a hindrance to a continuous conceptualization.

In this regard, in order to carry out a critical analysis of the effectiveness and dissemination of the most important CSR instruments, the macro area will be taken into account in the tools to implement socially responsible management systems (ethical codes, standards, guidelines, Balance sheets and reports). Choosing to consider this range of tools is due to their increasing diffusion, both at national and international level, and by the fact that, in socio-environmental reporting, such documents can be used in any kind of organization: profit, nonprofit and public administration.

In particular, the ethical codes, the Business Ethics Management tool of Anglo-Saxon origin, are affirmed in continental and Mediterranean Europe in the 1980s. They represent a volunteer-based tool, with which organizations define and enact their own behavioral and value orientations in the relationship with stakeholders, both internally and externally. These are devices aimed at managing a variety of issues, such as human rights protection, corruption, safety and health of workers, and the protection of the environment.

Generally, organizations adopt ethical code as an instrument of internal conduct in order to expose their socially responsible values and behaviors, to create a climate of trust and mutual cooperation, and to influence the behaviors of stakeholders. But, there are not only ethical codes as "internal" management tools for organizations, they can stand out:

- Model codes developed by professional companies and associations (trade unions, NGOs, auditors) to provide a reference benchmark for individual organizations; 
- Sector codes elaborated by certain industrial sectors and services addressed to individuals and/or organizations in which they belong;

- Negotiated codes, at European or International level, as social partners;

- Multi-stakeholder codes defined as a result of initiatives promoted by several social actors jointly;

- Intergovernmental codes that are achieved through the joining of organizations to international programs, which foresee the sharing of common goals and values.

Such heterogeneity is probably due to a degree of complexity and depth that varies depending on the scope in which the instrument is adopted.

The main advantages of adopting a code of ethics concern the promotion of their image and the improvement of relations with stakeholders and governance. In addition, this tool can be used by executives to monitor the internal and external stakeholder behavior lines in areas of broad and difficult to delimit, thus reducing the likelihood of incorrect interpretations and incorrect practices.

While one of the most critical aspects of this tool refers to its validity, or to its real effectiveness, which stems from the credibility and transparency of the same code of ethics. The credibility of the instrument depends on the objectives, the relevant areas of reference and the mechanisms implemented for the application of the principles set out. While transparency is concerned with the quality of communication systems, staff training and active stakeholder engagement.

In this regard, according to Manetti (2006), the decisive factor is the existence of a system of incentives and disincentives and, above all, of a widespread corporate culture on these aspects.

\subsection{Socio-environmental reporting: the main process and content standards}

Within CSR practices, the voluntary integration of socio-environmental objectives and activities into business processes and stakeholder relations and the resulting dissemination process of results are the response of the companies to emerging expectations and information needs arising from outside world. In this regard, socioenvironmental reporting represents the output of the process of building, presenting and communicating accounts of the social and environmental effects of the activities of organizations. During the 1990s, socio - environmental reporting documents were rapidly evolving, following the 1992 Rio de Janeiro Summit and the Fifth Community Environment Action Program, as awareness and awareness emerged, the urgency of reorienting production and consumption patterns towards the "sustainability" paradigm, understood in the broad sense of balancing the economic dimension with the environmental and social dimension (Supino and Sica 2011).

Socio-environmental reports, Social Report, Sustainability Report, Eco-Balances, Sustainability Report, etc., represent the many tools for socio-environmental reporting, along with many guidelines and standards prepared for its drafting, in order to strengthen its homogeneity, credibility and comparability. The most common and immediate method of classifying these tools is the one that distinguishes them in process standards and content standards.

Process standards give guidance on the characteristics that the management of a particular aspect of the activity must possess to be considered consistent with the assumption of RSI. The indications concern the basic elements for the correct setting of the management process, including in terms of bans and impediments, in order to ensure compliance with a minimum qualifying threshold for the assumption of RSI (Vitolla and Rubino 2012).

While content standards emphasize the characteristics that need to have the social reporting documents, and in particular highlight the aspects and subjects on which a RSI reporting needs to be provided. Among the process standards in this discussion are considered:

- AccountAbility 1000 (AA 1000). It was drafted in 1999 by the Institute of Social and Ethical Accounting (ISEA), an internationally recognized body of companies, NGOs, representatives of the world of universities and consulting companies, in order to improve credibility and authority Of the ethical-social reporting.

This tool is not certified, but is a useful tool for innovation and continuous improvement.

- Copenhagen Charter. Presented for the first time at a conference entitled Building stakeholder relation - the third international conference on social and ethical accounting, auditing and reporting in 1999 in Copenhagen, aims to provide a reference to organizations involved in the process of social orientation oriented to stakeholders. While, among the major socio-environmental reporting models that are related to content standards, they are reminded: Study Group on Social Budget (GBS). 
The mission of the group studio is to "develop and promote scientific research on the Social Report and on issues related to responsible business management processes in order to promote the diffusion of corporate social responsibility and its application in national and international contexts."

The latest revision of the reporting model (2013) explains all the guiding principles that will inspire the elaboration of the Social Report, such as transparency, accountability, comparability, periodicity and recurrence, significance and relevance, verifiability of information, trustworthiness and faithfulness representation (GBS 2013).

- Global Reporting Initiative (GRI). The purpose of GRI is to try to make the socio-environmental reporting document as close as possible to the levels of rigor, comparability, credibility and verifiability that characterize the financial statements. The guidelines have been revised over time and are currently in the GRI Sustainability Reporting Standards. These are standards that will enable organizations around the world to communicate their impact on the economy, the environment and society more transparently. The other international standard for voluntary use, Social Accountability 8000 (SA 8000), was drafted in 1997 by Social Accountability International (SAI), with the aim of providing support to organizations to promote the development and management of a responsive system Social, workable, verifiable and certifiable by independent third party bodies.

The SA 8000 model, for its implementation, refers to eight fundamental principles on: child labor, forced or compulsory labor, health and safety, freedom of association and right to collective bargaining, discrimination, disciplinary practices, working hours, remunerationIn addition to these requirements, the standard contemplates, at the ninth point, the implementation of a social responsibility management system, aimed at the continuous improvement of social performance, according to a logic that is based on the Deming Cycle.

This feature allows the SA 8000 to be coupled with the ISO 9001 and ISO 14001 standard quality and environmental management models issued by the International Organization for Standardization (ISO). In fact, the certification and easy integration with other management systems favored its dissemination, even though it has a "minimal" character for the implementation of RSI principles and practices. This is because it addresses only aspects related to workers' rights, whose protection in the countries of advanced economics and sociality is largely guaranteed by the regulations (Head 2007; Proto and Supino 2009). It is true that the standard reflects labor provisions contained in international conventions (ILOs, UN), supporting and integrating national labor laws throughout the world. Since its adoption, the standard has been subject to three revisions, more or less five years, the last of which has been drafted in 2014. Therefore, the current version of the SA 8000, which entered into force on 1 January 2015, will replace definitively the previous version (SA 8000: 2008) by June 30, 2017. This regularity in revising the standard ensures that it is continually applicable, aligning itself with the ongoing social issues (Social Accountability International 2017).

The latest issue of the latest edition of the standard concerns the introduction of the Social Performance Team (SPT), a figure that must be present in the organization in order to coexist with the other figures nominated by other management systems in place to reach managing an integrated template. Particularly significant is the standard terminology simplification and the introduction of the Risk Based Thinking concept that will allow periodic risk assessments (replacing the previous management review) to be used to identify and weigh current and potential risks with respect to the content of the risk SA8000: 2014, consulting interested parties and suggesting to senior management the actions to be taken to manage and prevent such risks. In addition, the team (SPT) prepared to perform these functions will have to ensure that the corrective and preventive actions defined by the organization are effectively implemented.

The team also has the task of implementing monitoring activities about the compliance of the organization with the standard, the actions taken by the organization downstream of the risk assessment, system effectiveness, and consistency with the policies adopted.

The greatest benefits of adopting a management model based on SA 8000 concern: an increase in credibility, transparency and image of the company, greater consumer confidence, and an improvement in the relationship with social institutions and organizations. Ethics along the supply chain, an improvement in the company's climate, as workers will feel protected by the company they work and will be more involved in achieving their goals, and an improvement in internal and external communications aimed at policy, commitments undertaken, and performance, in order to promote widespread dissemination of social responsibility practices and attitudes. 


\section{The socio-environmental dimension in SMEs}

The actions, models and tools for CSR are varied - and, as we have seen, ranging from ethical codes to environmental management systems, from ethical certification to social marketing to various types of socioenvironmental reporting tools. They are essentially designed for and for large companies, often operating in more than in several countries, and therefore more exposed to stakeholder pressures on environmental and social performance. This set of tools is therefore result hardly adoptable at SMES which constitute the backbone of the productive fabric of the current enlarged Europe and, as is well known, of our country.

In the Italian reality, however, compared to developed European economies, SMEs are characterized by peculiar elements of characterization, among which the average, in terms of number of employees, more reduced, the relative financial vulnerability as well as the prevailing structure of family type. The involvement of SMEs is therefore indispensable for the "building" of lasting sustainability, as it is capable of integrating growth in competitiveness, environmental protection and social development. This in consideration of the extraordinary synergies that may arise from the structured adoption of CSR-led pathways and the promotion of dynamic local development.

However, a careful analysis of national and international dynamics shows that the orientation of entrepreneurial organizations towards social responsibility reflects inevitably the company size. Indeed, the adoption of the relevant instruments is really small among SMEs, on the contrary, represents a prerogative of larger organizations.

The reasons for this are due to a multitude of reasons, among which it is worth highlighting that SMEs, on the one hand, show little knowledge of the practices and tools that can be adopted and, on the other, perceive an excessive difficulty and onerous. In fact, the proper implementation of social responsibility pathways requires specific skills and high organizational capacity, coupled with a strong focus on adequate and incisive communication policies: all these factors, generally absent in smaller organizations.

These factors must be flanked by other, including the limited availability of financial resources, which makes SMEs little inclined to make plans and investments with returns in the medium-long term, as moreover requires the realization of correct and effective social responsibility strategies and structured involvement and lasting of stakeholders.

However, although it is an aspect still little explored from a theoretical point of view, the investigations to the analysis of behavior and socio-environmental SMEs have highlighted a discreet attention in respect of aspects linked to CSR, both European and national level.

Indeed, such analyzes, based on real behavior towards the main stakeholders rather than the formal adoption of the instruments, affirm that the socio-environmental commitment is not a far-reaching or marginal element for SMEs and that they often put socially responsible. This is because, in the face of known weaknesses, SMEs have strong points, consisting of true and own peculiarities able to facilitate the path oriented toward a Triple Bottom Line Approach.

Suffice to think of the strong and immediate recognition of the entrepreneur's figure and its central role in making decisions, flexibility and ease of adaptation to changes in the context of reference, interpersonal relationships characterized by broad involvement with strong emphasis on human values and of the person, due to the widespread ability to develop a plot of positive relationships according to informality typical of small contexts. They are substantially constituted by a strong attention to the needs of employees and those of the territory, which often comes from the value system that drives the entrepreneur-owner, or the family of reference in the case of companies' family.

Moreover, the deep roots in the local socio-economic context of SMEs allows them a close link between enterprise and territory, recalling the modus operandi previous to the phenomenon of globalization, a link that feeds informal relationships and forms of mutual help. Productive Districts also often have a social value, which transforms them into areas of development of technical and commercial knowledge, entrepreneurial culture, educational and training structures, services to workers and their families. It is thus necessary to delineate innovative approaches, designed for SMEs, wherein the CSR should be interpreted as Company Stakeholders Responsibility in order to avoid the diffusion of "standard practices" and to promote "corporate behaviors" capable of effectively combining responsibility and competitiveness (Molteni and Todisco 2007). 
They will have to provide information and awareness-raising, able to put in light of the potential and reflections on the competitive performance. This creates a stable, systematic and planned link between socio-environmental commitment, stakeholder engagement, and enhancement of communication. Sometimes it is the low propensity to communicate, especially to the outside, which obscures social engagement in SMEs making them "operators silent" of RS.

Greater dissemination, transparency and communication of good practices and socially responsible behaviors could represent an important multiplier, capable of generating a sort of "domino effect" in a context such as that of SMEs, where imitation and re- interpretation are important ways of managing and organizing innovation. Particularly fruitful could be the adoption of network-based approaches or forms of collaboration between groups of undertakings at sectoral level or of territorial area or district, suitable to grasp the economies of scale and identifying real priorities for local intervention. In fact, in the case of small and very small organizations, the socio-environmental impact of the single actor is often insignificant, but becomes very significant when considering the district as a whole.

In this scenario, although the benefits in terms of image would be less as shared among the enterprises involved, even costs - the embodiment, discovery, monitoring, reporting - would become more sustainable, due to the distribution between the different actors concerned. Attention to socio-environmental aspects could become, for district businesses, an important lever of qualitative differentiation, capable of enhancing the wealth of intangible resources. Among them, the highest level of staff motivation, reputation among the social partners and, more generally, a renewed image of Made in Italy, where the social commitment represents a key factor in competitiveness and differentiation.

\section{The CSR in the Italian SMEs: the A. Petti S.p.A. experience}

In the SMEs Italian food, the company "Antonio Petti S.p.A." constitutes a reality representing the Italian sector of vegetable tinned. The A. Petti P.p.A. S.p.A., located in NoceraSuperiore (SA) operates from 1925 in the district of "Agro-Nocerino Sarnese" ${ }^{1}$ and is a well-known company producing processed tomatoes(Malandrino et al. 2017).In recent decades, the pressures emerging from the competitive arena in which the company A. Petti S.p.A. operates, have led management to redefine their approach, strategies, and organizational planning in order to achieve better economic, environmental and ethical performance (Salomone at al. 2013).

The A. Petti S.p.A. has therefore assumed precise economic, environmental and moral responsibilities, based on socially shared ethical principles, in response to a series of instances from the community and the territory, as well as from the institutional and economic context. Of course, in a symmetrical way, it has begun over time to progressively develop and subsequently adopt quality, environmental and social quality management programs.In this perspective, the A. Petti S.p.A. has also implemented an Integrated Management Systems that include an integrated approach, multiple quality dimensions according to ISO 9001, ISO 14001, SA8000 and Product Certifications (BRC and IFS).

Only recently, it has been equipped with tools of social responsibility to create a true good corporate citizenship, designed to provide guarantees, protection and support for the well-being of the community in which he operates. The corporate management, in fact, aware of the impacts of its activities on society and the environment, has tried to achieve a proper integration between the company's economic goals and social goals through voluntarily and consciously adopted policies. A. Petti Spa acknowledges that the responsibilities arising from the exercise of its activity go beyond the traditionally considered players, ie management, shareholders and creditors, to include a wider circle of stakeholders, including employees, suppliers, consumers and society in general, i.e. all those who in various capacities are affected by the consequences of corporate policies.

\footnotetext{
${ }^{1}$ The district of Agro NocerinoSarnese" has a specialization in the agri-food sector and reveals a significant interaction between the different phases of the system agribusiness, i.e. production and distribution of equipment, machinery and technical means, tasks properly agricultural and those relating to processing, storage and marketing of products.The nodal industry is that of vegetable preserves, in which they operate a plurality of small and medium-sized enterprises devoted principally to the processing tomatoes, representing about $65 \%$ of enterprises Italian canning.The Italian sector of vegetable preserves, however, in addition to representing an economic reality of absolute importance in the context of the agri-food sector national, in terms of number of enterprises, turnover, flows for export, etc., constitutes a driving element for the dissemination of quality products and for the affirmation of the Made in Italy.
} 
For several decades the company has been trying to get closer to local communities through philanthropic initiatives such as donations of money, charitable works, and job creation programs. Through these instruments, A. Petti S.p.A. has realized the first forms of social intervention aimed at pursuing social goals and at the same time spreading a positive image of consumers, workers and members of society in general.

However, these activities were sporadic and were not integrated into long-term business strategy or planning. Therefore, the management has rethought the corporate strategies in a socially responsible way. It has therefore taken initiatives that enable the organization to strive towards sustainable development through a trade-off between economic performance and environmental and social performance. This is to internalize and make the organization's social dimension tangible through careful consideration of the expectations of community members and the identification of objectives compatible with stakeholder interests.

Recently, A. Petti S.p.A. has implemented, within the Integrated Management System, the social responsibility management model SA8000, aimed at continuous improvement of social performance. It has therefore defined social policy with its objectives, has planned the necessary actions for their achievement, has also defined appropriate procedures for the selection, qualification and monitoring of suppliers and subcontractors, based on their ability to comply with the requirements of the standard. This is in order to activate a virtuous circle, aimed at involving a growing number of companies in the "ethical path".

The A. Petti S.p.A. envisaged the involvement of civil society in the process of monitoring the behavior of the company. This is through interviews with local organizations, trade union representatives and other stakeholders, both in the phase of obtaining certification and in the periodic monitoring of its maintenance.

\subsection{The CSR in A. Petti S.p.A: operational steps}

The path to transforming business ethics into a concrete CSR program has been marked by some particularly significant moments, outlined below.

\subsubsection{Integration of social goals into the company's mission}

Management has deliberately chosen to include social and ethical values among the goals to be pursued, regardless of any economic benefits that this may entail. It is in this way that aspects of the environment, the institutions, the centrality of the person and human rights, or the transparency of information and financial transactions are the subject of risk management strategies. To this end, an appropriate management training program on CSR has been implemented at this stage, which has provided the knowledge required to handle the issues in a conscious, organic and planned way. Given the continuous evolution of the subject, there are plans to organize periodic updating programs to maintain its modern and innovative strategies.

\subsubsection{Formal recruitment of social responsibility and enlargement of risk management strategies}

Management is aware that social commitment is not a point of arrival but, above all, a starting point that is realized when the pursuit of ethical, social and environmental values is officially consecrated in the acts defining the modalities and aims of the activity. To this end, A. Petti S.p.A. has developed, as the main instrument of selfregulation and implementation of ethical-social responsibility, the Code of Ethics. With the preparation of the Code of Ethics, A. Petti S.p.A. has defined and outlined the behavioral guidelines and the values that are inspired by its relationships with all stakeholders, both internal and external.

It has introduced a clear and explicit definition of the ethical and social responsibilities of each participant in the organizational structure of stakeholder groups, laying the foundations for a fair and effective management of transactions and human relations, and supporting the reputation of the To create a climate of trust and mutual cooperation.

A crucial role played, therefore, constant commitment assumed by A. Petti S.p.A. promoting the knowledge of the Code by all the members of the organization and other stakeholders who directly or indirectly interact with it. From constructive dialogue with the various stakeholders, in fact, a process that, through listening to the instances and balancing them with the company's strategies, aims to activate a virtuous circle aimed at continuous improvement of its performance.

A. Petti S.p.A. provided for the establishment of a Supervisory Body (the Ethics Committee) with powers of initiative and control, with the task of monitoring, through appropriate procedures, the operation and compliance of the Code, as well as the Ensure that you upgrade. The system of implementation and control of the Code of Ethics of A. Petti S.p.A. 
it also envisages the identification of an Ethics Officer who has the operational responsibility of the corporate ethics program and educates the Ethics Committee - which is hierarchically dependent - executes its decisions and informs it of its activities.

A. Petti S.p.A. also uses an Internal Ethical Auditing, an independent and objective activity of assurance and support, aimed at improving the efficiency and efficiency of the organization. The implementation of codes of conduct through concrete management tools thus becomes a further statement of the real will of the organization to take on the concerns of the stakeholders and to meet ethical and social values that, primarily addressed to the global community, will end in the long run represent for the enterprise a real added value, of a type also economical.

\subsubsection{Identifying stakeholders}

Once integrated, even formally, social commitment within the goals to be achieved, it was necessary to implement it first in favor of those individuals, entities or social groups that can be made part of the notion of stakeholders. Since the stakeholder concept has led to a fairly wide-ranging approach, at this stage, corporate management first identified in a more detailed way by defining a stakeholder map, which are the most likely to have the negative consequences of the activity of the company (figures 1 ).

Figure 1 - Stakeholders map of A. Petti S.p.A.

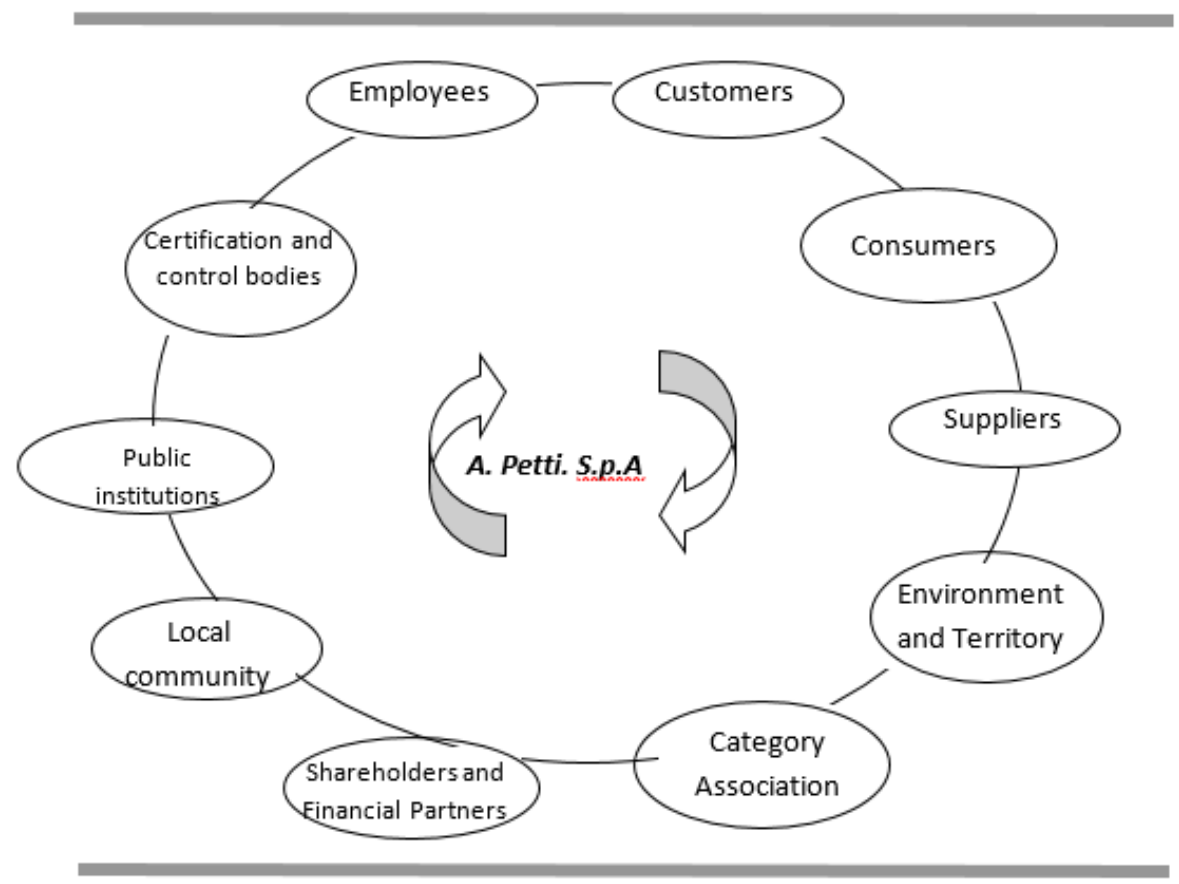

With respect to that community, A. Petti S.p.A. has implemented appropriate policies for containment and prevention of social costs, and established transparent forms of dialogue and involvement with their representatives.

The behaviors that characterize the modus operandi of each participant in the organizational structure of A. Petti S.p.A., in fact, are based on the observance of the law, regulations, and statutory provisions, codes of selfdiscipline, ethical integrity and fairness in a framework of transparency, honesty, good faith and full respect for the competition rules. In particular, the growth strategy of A. Petti S.p.A. is based on the following values:

\section{$>$ Transparency}

In the conduct of its relations A. Petti S.p.A.provides its interlocutors with clear, complete and timely access to useful information to correctly and transparently interpret the economic, social and environmental impacts of their business activities.

\section{$>$ Correctness}

All the actions, operations and negotiations carried out and, in general, the behaviors put in place by the members of the organization in the course of the work are inspired by the utmost fairness, honesty, clarity and legitimacy in the formal aspect and substantial. 


\section{Consistency}

For A. The breasts S.p.A., be consistent means to undertake to adopt and maintain over time a carried out in line with the values, the mission and the principles of operation of the company. They are considered to be the foundation of strategic planning, objectives and operational management and also contribute to determining its corporate identity and entrepreneurial philosophy. Similarly, under the same conditions, A. Petti S.p.A. It prefers the interlocutors who, in their behaviors, are consistent with their values.

\section{$>$ Professionalism}

All A. Petti S.p.A. activities must be carried out with professional commitment and rigor, respecting the roles and responsibilities assigned, in order to protect the prestige and reputation of the company. The goals of the organization, the proposal and the implementation of projects, investments and actions are aimed at increasing the company's assets, management, technology and knowledge values, as well as the creation of value and well-being for all Stakeholders in the long-term.

Bribery, illegal favors, collusive behavior, stress, direct and/or third party, personal and career benefits for themselves or others are without exception prohibited.A. Petti S.p.A. uses multiple tools for stakeholder engagement ranging from on-line consultations to individual meetings and/or interviews, as well as specific surveys to check the concerns of certain stakeholder groups on some critical aspects.Identifying stakeholders as recipients of formalized safeguards in codes of conduct and providing accurate risk management tools for the pursuit of social goals brings with it a clear awareness of the value and benefits of a business-oriented policy prevention.

This is to assess ex ante and avoid pipelines that can also cause high social costs, such as environmental or occupational safety, where appropriate measures can prevent or minimize the risk of accidents. In addition, the responsibility for implementing an internal control system and an effective risk management system is common at every level of the organizational structure of A. Petti S.p.A. As a result, all members of the organization, within the functions and responsibilities covered, are committed to defining and actively participating in the proper functioning of the internal control and risk management system.

\subsubsection{Identification and monitoring of social performance indicators and external communication.}

The management of A. Petti S.p.A. identified and defined a set of essential social performance indicators to make the trade-off achieved between economic, social and environmental goals as transparent as possible.A proper assessment of the effects that a socially responsible policy results in, in fact, necessarily passes through a prior identification of the parameters to which a given commitment is assumed.This, so that we can secure the initial values which will constitute the reference basis for calculating changes over time, and thus be able to check whether the commitment in the better previously assumed was maintained, i.e. if there have been significant changes, or again, in extremis, if there were even a few deteriorations compared to the initial situation. With the definition of social performance indicators prepared and drafted by the intervention of super parts providing guarantees of independence, A. Petti S.p.A. makes converge in the review ${ }^{2}$ that draws up the company's social performance data annually.

On the basis of this data the management establishes a critical comparison with stakeholders about the company's activities with regard to the achievement of the non-economic goals. This comparison is the starting point to redraw the strategies up to that timed followed, correcting, replacing and eliminating strategies that have not produced the expected outcomes, and maintaining, innovating and implementing those that instead have fulfilled the expectations, or are even go beyond. In this way, the company will be ready to start its CSR plan for the next period even more consciously and efficiently.

A. Petti S.p.A. also informs its internal and external stakeholders of its principles and norms of behavior by advertise the Code of Ethics through its own website and through specific communication activities (such as delivery to all employees internal and external copies of a copy of the Code at the time of the hire or start of the collaboration relationship or the inclusion of an informative note on the adoption of the Code in all contracts, etc.).

\footnotetext{
${ }^{2}$ The review originates from a systemic evaluation of the Management System to verify its adequacy, effectiveness and efficiency and identify possible opportunities to improve its performance, possibly also making appropriate modifications to the System itself and, therefore, Defining new goals and new assumptions of responsibility.
} 
In order to ensure the correct understanding of the values and principles set out in the Code of Ethics for all employees, A. Petti S.p.A. provides a training activity aimed at creating a sharing on the contents of the Code itself, also providing tools for awareness and knowledge of mechanisms and procedures to translate ethical principles into behaviors to be held concretely in day-to-day operations.In particular, the training initiatives are implemented with modalities and content appropriate to the role played role in the company from each collaborator and developed according to a path to completing vocational training and enhancing personal development.

\section{Future Research}

The case study presented provides an extended reinterpretation of the concept of Social Responsibility built on the central role of the internal and external stakeholders and on the nature and variety of their relationships according to which the PMI can be a driving force of change processes and favors sustainability as a correct, fair and transparent form of value creation for all stakeholders.

The peculiarity of this process of creating and distributing value is related to its ineffective internalization of benefits to internal stakeholders as it can generate positive externalities (e.g. market or non-market externalities).

Positive externalities are the benefits for the reference population, which are generated by unintended investment decisions by companies and organizations. Non-intentionality is that only a part of the created return remits private investment decisions.

According to the taxonomy of the literature review, the tools analyzed and the results emerged from the case study, it appears the possibility of following for future research a methodological approach of co-evolutionary (Dopfer et al., 2004) along two lines of analysis:

$>$ From micro to meso level: the reiteration and ossified of behaviors of an organization inspired by the extended interpretation of CSR activating mechanism of propagation like us imitation and networking between the many actors working in the context of reference generating a virtuous circle.

$>$ From meso to macro level: the emergence of a virtuous circle can in turn favor a process of accumulation of shared CSR rules and of an intangible capital for the sustainable path of economic change.

\section{Bibliografia}

Associazione nazionale per la ricerca scientifica sul Bilancio Sociale (2013). Il Bilancio Sociale. GBS 2013 Principi di redazione del Bilancio Sociale.Milano: Giuffrè Editore. [Online] Available: http://www.gruppobilanciosociale.org/wp-content/uploads/2014/02/Standard-GBS-2013-Principi-diredazione-del-Bilancio-Sociale.pdf.(April 22, 2017).

Bowen, H. (1953). Social responsibility of the businessman.New York: Harper \& Row.

Carroll, A.B. (1979). A three dimensional model of corporate social performance.Academy of Management Review, 4 (4),497-505.

Carroll, A.B. (1991). The Pyramid of Corporate Social Responsibility. Business Horizons, 34 (4), 39-48.

Carroll, A.B. (2007). La piramide della CSR: verso uno stakeholder management morale. In R.E. Freeman, G. Rusconi, \&M. Dorigatti (Eds.) Teoria degli Stakeholder. Milano:Franco Angeli.

Cheng, B., Ioannou, I., \&Serafeim, G. (2014). Corporate Social Responsability and access to finance. Strategic Management Journal, 35(1), 1-23.

Citterio, A., \&Lenzi, I. (2005). Reti di territori, reti di responsabilità sociale. Rapporto sullo sviluppo sostenibile.Fondazione Eni Enrico Mattei, n. 8.

Dopfer, K., Foster, J., \&Potts,J. (2004).Micro-Meso-Macro.Journal of Evolutionary Economics, 14, 163-219.

European Commission (2001). Green Paper. Promoting a European framework for Corporate Social Responsibility. Brussels.[Online] Available:

https://eur-lex.europa.eu/legal-content/EN/TXT/PDF/?uri=CELEX:52001DC0366\&from=IT (September 2, 2017).

Freeman, R.E. (1984). Strategic management. A stakeholder approach. Boston: Pitman Publishing Inc.

Friedman, M. (1962). Capitalism and Freedom.Chicago: Chicago University Press.

ILO (2017). Tripartite Declaration of Principles concerning Multinational Enterprises and Social Policy. [Online] Available: http://www.ilo.org/empent/Publications/WCMS_094386/lang--en/index.htm.(May 17, 2017). 
Malandrino, O., Sica, D., \&Supino, S. (2017).Integrated Management Systems: the A. Petti Spa experiences.Paper presented in M2D2017 - 7th International Conference on Mechanics and Materials in Design, Albufeira (Algarve)/Portugal, June. In press

Manetti, G. (2006). Il triple bottom line. Dal coinvolgimento degli stakeholder alle verifiche esterne.Milano: FrancoAngeli.

Molteni, M., \&Todisco, A. (2007). Piccole e Medie Imprese e CSR. La CSR come leva di differenziazione. CSR Manager Network Italia.

Molteni, M. (2006). Responsabilità sociale e performance d'impresa. Per una sintesi socio-competitiva, Vita e Pensiero. Milano.

Nigro, C., \&Petracca, M. (2016). La CSR dalle origini all'approccio neo-istituzionalista.Torino: Giappichelli Editore.

Proto, M., \&Supino, S. (2009). Dal Management Ambientale alla Responsabilità Sociale delle Organizzazioni. Stato dell'arte e dinamiche evolutive.Torino: Giappichelli Editore.

Salomone, R., Clasadonte, M.T., Proto, M., \&Raggi, A. (Eds.) (2013).Product-Oriented Environmental Management System (POEMS) - Improving Sustainability and Competitiveness in the agri-food chain with innovative environmental management tools. Springer, 29-53.

Social Accountability International (2014). SA 8000 standard.[Online] Available: http://www.saintl.org/_data/global/files/SA8000Standard2014(3).pdf.(March 22, 2017).

Supino, S., \&Sica, D. (2011). Nuovi paradigmi di rendicontazione d'impresa: il report integrato. Esperienza d'Impresa, 2, 81-91.

Vitolla, F., \&Rubino, M. (2012). Il reporting socio-ambientale e di sostenibilità. Contenuti della disclosure e qualità delle informazioni.Milano: Egea.

Viviani, M. (1999). Specchio magico. Il bilancio sociale e l'evoluzione delle imprese.Bologna:Il Mulino. 